\title{
Micropropagação de abacaxi ornamental (Ananas comosus var. bracteatus) por meio da indução ao estiolamento e regeneração de plântulas
}

\author{
ANA CRISTINA PORTUGAL PINTO DE CARVALHO', EMÍLIA PINTO BRAGA", \\ MAURÍCIO REGINALDO ALVES DOS SANTOS ${ }^{1,2}$, JOÃO PAULO SARAIVA MORAIS ${ }^{1}$
}

\begin{abstract}
RESUMO
O mercado de flores tropicais está em franca expansão, sendo crescente a comercialização de abacaxi ornamental como flor de corte. Segmentos nodais estiolados são utilizados para a micropropagação em várias culturas. O objetivo deste trabalho foi avaliar a multiplicação in vitro de segmentos nodais estiolados para produção de mudas de abacaxi ornamental, Ananas comosus var. bracteatus. Talos, obtidos a partir de plântulas produzidas in vitro, foram inoculados em meio MS e mantidos no escuro, a $24 \pm 1^{\circ} \mathrm{C}$. Os tratamentos foram: MS sem reguladores de crescimento; $\mathrm{MS}+10 \mu \mathrm{M}$ de ANA; MS + 10 $\mu \mathrm{M}$ de AIA e MS + 10 $\mu \mathrm{M}$ de AIB. Ao final de 60 dias, avaliouse número de brotos/talo, número de nós/broto, comprimento do broto, comprimento médio dos internós e total de nós/talo. Não houve diferença no número de brotos estiolados por talo entre os tratamentos avaliados. O meio MS sem reguladores de crescimento apresentou o maior valor para o número de nós/broto como para o número total de nós/explante, diferindo estatisticamente dos meios contendo AIB e ANA para a primeira variável e AIA e ANA, para a segunda. Quanto ao comprimento do broto e o comprimento médio dos internós, os menores valores foram obtidos no meio contendo ANA. Para a regeneração de plântulas, foram utilizados segmentos nodais contendo dois nós, oriundos de talos estiolados in vitro por 60 dias no meio MS, sem regulador de crescimento, no escuro. Os tratamentos foram: MS sem reguladores de crescimento; MS + 4,44 $\mu \mathrm{M}$ de BAP; MS + 8,88 $\mu \mathrm{M}$ de $\mathrm{BAP}$ e $\mathrm{MS}+13,32 \mu \mathrm{M}$ de BAP. Os frascos foram incubados sob fotoperíodo de 16 horas, a $24 \mathrm{a} \pm 1^{\circ} \mathrm{C}$. Ao final de 30, 45 e 60 dias foi avaliado o número de plântulas obtidas por nó. Aos 30 dias, não houve diferença no número de plântulas/nó entre os tratamentos testados. Após 45 dias, 13,32 $\mu \mathrm{M}$ de BAP promoveu maior número de plântulas regeneradas por nó, que diferiu estatisticamente do meio sem a adição dessa citocinina. Aos 60 dias, esse mesmo meio proporcionou o maior número de plântulas por nó, diferindo estatisticamente do meio MS sem a adição de regulador de crescimento e do meio acrescido de BAP, na concentração de 4,44 $\mu \mathrm{M}$.
\end{abstract}

Palavras-chave: cultura de tecidos, micropropagação, propagação de plantas.

\begin{abstract}
Micropropagation of ornamental pineapple (Ananas comosus var. bracteatus) by plantlets etiolation and regeneration. The market of tropical flowers is expanding, and the marketing of ornamental pineapple inflorescence is also increasing. Etiolated nodal segments are used for micropropagation of several crops. The aim of this work was to evaluate the use of etiolated nodal segments for micropropagation of ornamental pineapple Ananas comosus var. bracteatus. Stems obtained from in vitro subcultured plantlets were inoculated, in medium MS and stored in darkness at $24 \pm 1^{\circ} \mathrm{C}$. Four treatments were used: MS without growth regulators; MS $+10 \mu \mathrm{M}$ of naphtalenacetic acid (NAA); $\mathrm{MS}+10 \mu \mathrm{M}$ of indolacetic acid (IAA); $\mathrm{MS}+10 \mu \mathrm{M}$ of indolbutiric acid (IBA). At the end of 60 days were evaluated: number of etiolated shoots/stem; number of nodes/etiolated shoot; etiolated shoot length, internode length and total number of nodes/stem. There was no difference in the number of etiolated shoots per explant among the evaluated treatments. The medium MS without growth regulators produced greater number of nodes per etiolated shoot and of total number of nodes per explant, differing statistically from the media with IBA and NAA for the first variable and IAA and NAA for the second one. The lowest values for etiolated shoot length and for internode distance were obtained at the medium with NAA, and the other treatments did not differ significantly among themselves. Nodal segments having two nodes obtained from in vitro etiolated stems were placed for 60 days in medium MS without growth regulators to plantlet regeneration. The treatments were: MS without growth regulators; $\mathrm{MS}+4,44 \mu \mathrm{M}$ of 6-benzylaminopurine (BA); $\mathrm{MS}+8,88 \mu \mathrm{M}$ of BA; MS + 13,32 $\mu \mathrm{M}$ of BA. The flasks were incubated under photoperiod of 16 hours, at $24 \pm 1^{\circ} \mathrm{C}$. At the end of $30,45,60$, days were evaluated the number of regenerated plantlets per node. At 30 days, there was no difference in the number of regenerated plantlets/node among the tested treatments. At 45 days, 13,32 $\mu \mathrm{M}$ of BA did promote the highest number of regenerated plantlets, which differed from the medium MS without the addition of this cytokinin. At the 60 days, this same medium did promoted the highest number of plantlets per node, differing statistically from medium MS without growth regulators and from the one supplemented with $4,44 \mu \mathrm{M}$ of BA.
\end{abstract}

Key-words: tissue culture, micropropagation, plant propagation.

\footnotetext{
(1) Laboratório de Cultura de Tecidos e Genética Vegetal, Embrapa Agroindústria Tropical, Caixa Postal 3761, 60.511-110, Fortaleza (CE). E-mail: cristina@ cnpat.embrapa.br ${ }^{(2)}$ Bolsista do CNPq
} 


\section{INTRODUÇÃO}

Os abacaxis ornamentais, nativos da flora brasileira, vêm sendo bastante utilizados, não somente no Brasil, mas também na Europa e nos Estados Unidos. As principais espécies comercializadas de abacaxi ornamental são: Ananas comosus var. erectifólius e A. comosus var. bracteatus, sendo a primeira de maior expressão. De acordo com *BAIMA, em 2003, as exportações de abacaxi ornamental no Ceará alcançaram US\$298,9 mil, sendo os principais destinos Holanda (72\%), Alemanha (13\%) e Portugal $(9, \%)$.

Normalmente, os plantios de abacaxi ornamental têm sido feitos com mudas propagadas vegetativamente, sendo estas retiradas de diferentes partes da planta: coroa, filhote e rebentão (BORGES et al., 2003), método semelhante ao do plantio de abacaxi comestível. Em abacaxizeiro comestível esse processo pode ocasionar a disseminação do patógeno causador da fusariose (CABRAL et al., 1985). A micropropagação apresenta-se como uma alternativa viável de propagação vegetativa. Permite obter maior taxa de multiplicação quando comparada aos métodos tradicionais de propagação, e ainda plantas com alta qualidade fitossanitária e estabilidade genética, em menor período de tempo, independente da época do ano (CORREIA et al., 1999a). A utilização de mudas produzidas em laboratórios no Brasil, de abacaxi ornamental, ainda é muito restrita, pelo reduzido número de laboratórios, preço relativamente alto e também por ser uma atividade recente. Além disso, o principal método utilizado atualmente consiste na proliferação de gemas axilares (CORREIA et al., 1999a,b; BORGES, 2000; BORGES et al., 2003; BRAGA et al., 2003). Nesse sistema é comum ocorrerem simultaneamente a proliferação de gemas axilares e a formação de gemas adventícias na base do explante. Entretanto, conforme ressaltam GRATTAPAGLIA \& MACHADO (1998), sob o aspecto de integridade clonal, as gemas adventícias são desejáveis como sistema de multiplicação, desde que a formação de calo seja mínima ou nula.

A produção de mudas in vitro de abacaxi comestível (Ananas comosus L. Merr.), por meio de segmentos nodais estiolados foi relatada por MOREIRA et al. (1997), KISS et al. (1995), PEREIRA et al. (2001) e BARBOZA \& CALDAS (2001). Esse método tem a vantagem de evitar lesões na zona de regeneração, impedindo a formação de calo, e conseqüentemente proporcionando baixos níveis de variabilidade fenotípica (KISS et al., 1995).

O objetivo deste trabalho foi estabelecer um protocolo para multiplicação in vitro de abacaxi ornamental Ananas comosus var. bracteatus, induzindo o estiolamento de segmentos nodais e posterior regeneração de plântulas. A partir desse método pretende-se minimizar a variabilidade fenotípica observada em outros métodos de micropropagação.

\section{MATERIAL E MÉTODOS}

O trabalho foi realizado no Laboratório de Cultura de Tecidos e Genética Vegetal da Embrapa Agroindústria Tropical (CNPAT), em Fortaleza, Ceará.

\subsection{Estiolamento}

Foram utilizados como explantes plântulas de Ananas comosus var. bracteatus, estabelecidas in vitro com altura de 2 a $3 \mathrm{~cm}$, das quais foram eliminadas todas as folhas, deixando-se apenas o talo. O meio de cultura básico utilizado foi o MS (MURASHIGE \& SKOOG, 1962), suplementado com sacarose 30 g.L.-1, e solidificado com ágar a 4,5 g. $\mathrm{L}^{-1}$. O pH foi ajustado para 5,8 antes da autoclavagem, que foi realizada a $121^{\circ} \mathrm{C}$, por 15 minutos.

Os explantes (talos) foram inoculados individualmente em tubos de ensaio com $150 \mathrm{~mm}$ x 25 $\mathrm{mm}$, contendo $15 \mathrm{~mL}$ de meio de cultura, e mantidos em sala de crescimento, a $24 \pm 1^{\circ} \mathrm{C}$, no escuro.

$\mathrm{O}$ delineamento experimental foi inteiramente casualizado, constituído de quatro tratamentos e quatro repetições, sendo a unidade experimental constituída por seis explantes. Foram testados os seguintes tratamentos: 1) $\mathrm{MS}$ sem regulador de crescimento; 2$) \mathrm{MS}+10 \mu \mathrm{M}$ de ácido indolacético (AIA); 3) $\mathrm{MS}+10 \mu \mathrm{M}$ de ácido indolbutírico (AIB) e 4) $\mathrm{MS}+10 \mu \mathrm{M}$ de ácido naftalenoacético (ANA).

As avaliações ocorreram após 60 dias, observandose o número de brotos por explante, número de nós por broto, comprimento dos brotos e comprimento dos internós. O número total de nós por explante foi obtido a partir da multiplicação do número de brotos estiolados/ explante pelo número de nós/broto. Os dados foram submetidos à análise de variância e as médias foram comparadas pelo teste de Tukey a $5 \%$ de probabilidade.

\subsection{Regeneração}

Para regeneração de plântulas foram utilizados, como explantes, brotos estiolados in vitro, após 60 dias de cultivo no meio de cultura MS sem regulador de crescimento, no escuro. A escolha desses brotos foi em função do maior número de nós formados nesse meio de cultura. Eles foram divididos em segmentos contendo apenas dois nós, sendo estes colocados horizontalmente, em frascos com capacidade de $220 \mathrm{~mL}$, contendo $30,0 \mathrm{~mL}$ de meio de cultura.

O delineamento experimental foi inteiramente casualizado, utilizando-se os seguintes tratamentos: 1) MS sem regulador de crescimento; 2) MS + 6benzilaminopurina (BAP) a 4,44 $\mu \mathrm{M}$; 3) $\mathrm{MS}+\mathrm{BAP}$ a 8,88 $\mu \mathrm{M}$ e 4) $\mathrm{MS}+\mathrm{BAP}$ a $13,32 \mu \mathrm{M}$. Foram utilizadas cinco repetições, sendo cada unidade experimental constituída por um frasco contendo quatro segmentos, com dois nós cada. As culturas foram mantidas em sala de incubação com intensidade luminosa de $30 \mu \mathrm{mol} . \mathrm{m}^{-2} \mathrm{~s}^{-1}$, a $24 \pm 1^{\circ} \mathrm{C}$, e fotoperíodo de 16 horas.

Aos 30, 45 e 60 dias, procedeu-se à contagem do número de plântulas regeneradas por nó.

Os dados foram submetidos à análise de variância e as médias foram comparadas pelo teste de Tukey a 5\% de probabilidade.

\section{RESULTADOS}

Como se pode observar na tabela 1 , o número de brotos estiolados (Figura 1) por explante variou de 1,21 a 1,96 , mas não foram identificadas diferenças significativas 
entre os tratamentos testados. O comprimento dos brotos foi inferior no meio contendo ANA $(1,78 \mathrm{~cm})$, em relação aos outros tratamentos, cujos valores foram estatisticamente equivalentes e variaram de 5,50 a $6,19 \mathrm{~cm}$. O mesmo foi observado com relação ao comprimento dos internós, pois os valores obtidos nos meios sem regulador, com AIB e AIA, foram equivalentes entre si (variando de 0,80 a $1,06 \mathrm{~cm}$ ) e superiores aos obtidos no meio contendo ANA $(0,50)$. O número médio de brotos estiolados produzidos por explante inicial foi estatisticamente igual em todos os tratamentos. O comprimento médio dos brotos e a distância média entre os nós foram estatisticamente inferiores no meio contendo ANA. O número de nós por broto foi numericamente superior no meio MS sem a adição de regulador de crescimento $(7,75)$, estatisticamente equivalente ao tratamento com $\operatorname{AIA}(5,90)$, e superior aos meios com AIB $(5,43)$ e ANA $(3,14)$. O meio sem reguladores de crescimento apresentou também o maior valor para número total de nós por explante $(9,80)$, sendo estatisticamente igual ao valor obtido no meio adicionado de $\operatorname{AIB}(8,25)$ e superior aos meios contendo AIA $(6,62)$ e ANA $(6,17)$.

Tabela 1. Número de brotos estiolados por explante, número de nós por broto, comprimento de brotos, distância entre os nós e número total de nós por explante de abacaxi ornamental Ananas comosus var. bracteatus, em diferentes tratamentos, após 60 dias no escuro ${ }^{(1)}$.

\begin{tabular}{lccccc}
\hline Meio de cultura & \multicolumn{5}{c}{ Características avaliadas } \\
\cline { 2 - 6 } & $\begin{array}{c}\text { Número de } \\
\text { brotos/explante }\end{array}$ & $\begin{array}{c}\text { Número de } \\
\text { nós /broto }\end{array}$ & $\begin{array}{c}\text { Comprimento } \\
\text { de brotos (cm) }\end{array}$ & $\begin{array}{c}\text { Distância entre } \\
\text { os nós (cm) }\end{array}$ & $\begin{array}{c}\text { Número total } \\
\text { de nós/explante }\end{array}$ \\
\hline MS sem reguladores & $1,38 \mathrm{a}$ & $7,75 \mathrm{a}$ & $6,19 \mathrm{a}$ & $0,80 \mathrm{a}$ & $9,80 \mathrm{a}$ \\
MS + AIA a 10 $\mu \mathrm{M}$ & $1,21 \mathrm{a}$ & $5,90 \mathrm{ab}$ & $5,50 \mathrm{a}$ & $0,89 \mathrm{a}$ & $6,62 \mathrm{~b}$ \\
MS + AIB a 10 $\mu \mathrm{M}$ & $1,63 \mathrm{a}$ & $5,43 \mathrm{~b}$ & $6,06 \mathrm{a}$ & $1,06 \mathrm{a}$ & $8,25 \mathrm{ab}$ \\
MS + ANA a 10 $\mu \mathrm{M}$ & $1,96 \mathrm{a}$ & $3,14 \mathrm{c}$ & $1,78 \mathrm{~b}$ & $0,50 \mathrm{~b}$ & $6,17 \mathrm{~b}$ \\
CV \% & 33,21 & 17,28 & 18,93 & 14,71 & 18,22 \\
\hline
\end{tabular}

(!) Médias seguidas da mesma letra, na coluna, não diferem entre si pelo teste de Tukey a 5\% de probabilidade.
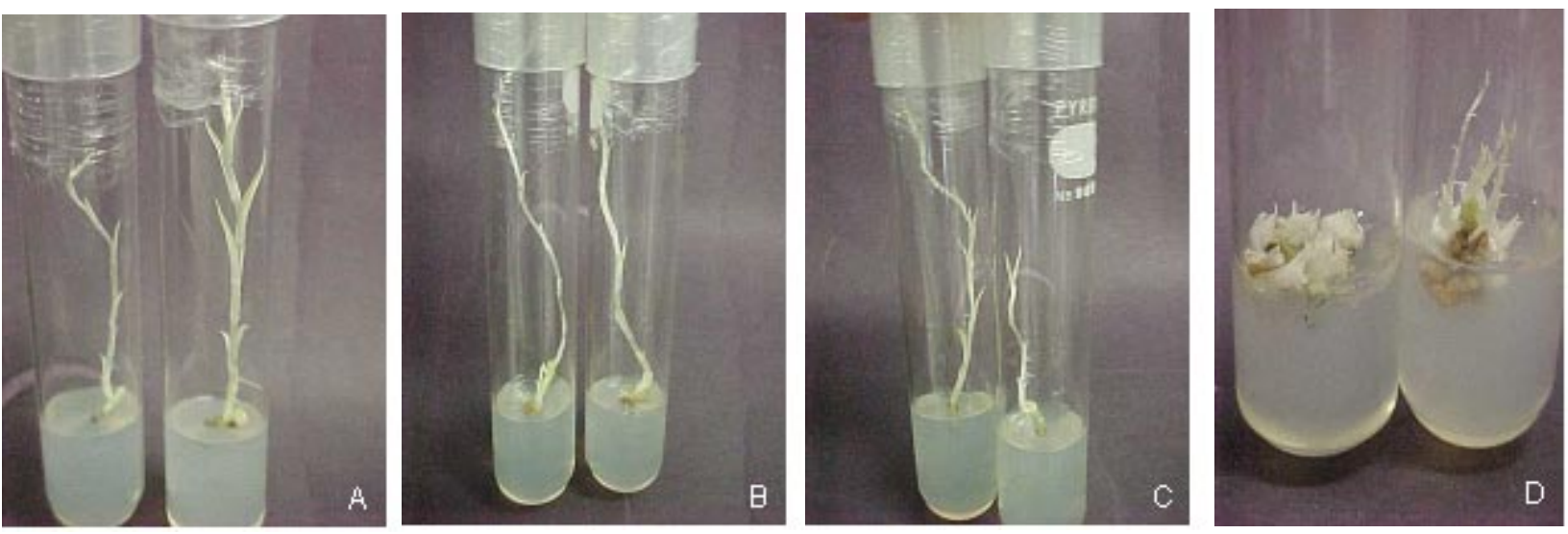

Figura 1. Brotos de abacaxi ornamental Ananas comosus var. bracteatus estiolados nos meios: MS sem reguladores (A), MS com $10 \mu \mathrm{M}$ de AIB (B), MS com $10 \mu \mathrm{M}$ de AIA (C), MS com $10 \mu \mathrm{M}$ de ANA (D), após 60 dias no escuro.

Aos 30 dias, não houve diferença no número de plântulas regeneradas por nó entre os tratamentos testados. Aos 45 dias, o BAP promoveu maior número de plântulas regeneradas por nó, com uma média de 1,76 , no meio contendo $13,32 \mu \mathrm{M}$, que diferiu estatisticamente do meio sem a adição dessa citocinina, aos 45 dias. Já aos 60 dias, esse mesmo meio proporcionou o maior número de plântulas (Figura 2) por nó (2,03), diferindo estatisticamente do meio sem a adição de regulador de crescimento e do meio acrescido de BAP, na concentração de 4,44 $\mu \mathrm{M}$ (Tabela 2).

\section{DISCUSSÃO}

O número médio de brotos estiolados produzidos por explante (talo) foi estatisticamente igual em todos os tratamentos, aos 30 dias de incubação no escuro. Tais resultados confirmam os obtidos por BARBOZA \& CALDAS (2001), que não registraram diferenças significativas para o número de brotos formado por explante do abacaxi híbrido PE x SC-52, em diferentes tratamentos, após 35 dias no escuro. O maior número de brotos, registrado pelos autores, foi de 1,4 por explante. Neste trabalho, o maior valor alcançado para essa característica foi 1,96. 
Tabela 2. Número de plântulas regeneradas por nó, em diferentes meios de cultura, a partir de segmento estiolado, do abacaxi ornamental Ananas comosus var. bracteatus. ${ }^{(1)}$

\begin{tabular}{lccc}
\hline \multirow{2}{*}{ Meio de cultura } & \multicolumn{3}{c}{ Período de cultivo } \\
\cline { 2 - 4 } & $\mathbf{3 0 \text { dias } ^ { ( 2 ) }}$ & $\mathbf{4 5}$ dias & $\mathbf{6 0}$ dias \\
\hline MS sem reguladores & $0,60 \mathrm{a}$ & $0,79 \mathrm{~b}$ & $0,90 \mathrm{~b}$ \\
MS + BAP a 4,44 $\mu \mathrm{M}$ & $0,85 \mathrm{a}$ & $1,13 \mathrm{ab}$ & $1,13 \mathrm{~b}$ \\
MS + BAP a 8,88 $\mu \mathrm{M}$ & $1,01 \mathrm{a}$ & $1,33 \mathrm{ab}$ & $1,33 \mathrm{ab}$ \\
MS + BAP a 13,32 $\mu \mathrm{M}$ & $0,83 \mathrm{a}$ & $1,76 \mathrm{a}$ & $2,03 \mathrm{a}$ \\
$\mathrm{CV} \%$ & 42,12 & 36,56 & 30,99 \\
\hline
\end{tabular}

(1) Médias seguidas da mesma letra, na coluna, não diferem entre si pelo teste de Tukey a 5\% de probabilidade.

${ }^{(2)}$ Número de dias após inoculação dos explantes nos meios de cultura.

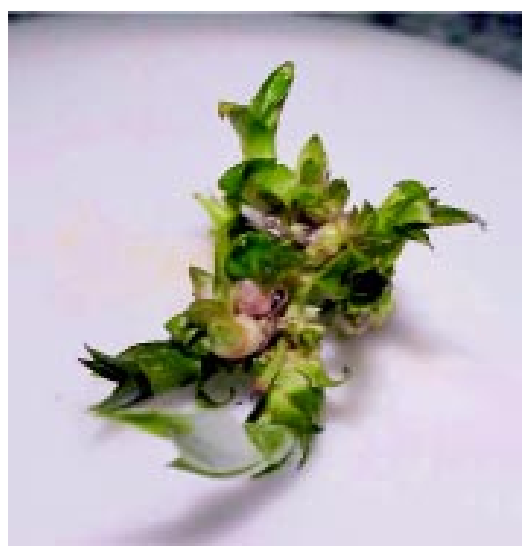

Figura 2. Plântulas de abacaxi ornamental Ananas comosus var. bracteatus regeneradas em meio MS com BAP a 13,32 $\mu \mathrm{M}$, após 60 dias de inoculação.

BARBOZA \& CALDAS (2001) trabalhando com abacaxi comestível, Ananas comosus (híbrido PE x SC-52), ao final de 60 dias, também no escuro, registraram, em média, 11,3 nós por broto estiolado, na presença de ANA. O número médio de nós obtido por broto, para A. comosus var. bracteatus, em meio de cultura contendo essa mesma auxina, foi de 3,14.

As várias auxinas apresentam respostas diferentes in vitro. AIA é considerada uma auxina instável, que se degrada facilmente pela luz. Essa instabilidade, aliada à sua inativação ou destruição metabólica nas células, a torna uma auxina relativamente "fraca", comparada com outras (CALDAS et al., 1990). BARBOSA \& CALDAS (2001) obtiveram maior número de nós por broto estiolado no meio contendo ANA, em relação ao meio suplementado com AIA, trabalhando com A. comosus. Contrariando esses resultados, no presente trabalho, o número médio de nós obtido por broto estiolado, no meio contendo AIA, foi superior ao obtido no meio acrescido de ANA.

No escuro, as plantas se tornam estioladas, isto é, investem energia no alongamento rápido da parte aérea, não ocorrendo a expansão foliar nem a formação do sistema fotossintético funcional (GEORGE, 1993a). Os brotos estiolados obtidos apresentaram coloração branca, indicando ausência ou reduzida atividade fotossintética dos explantes. Além disso, as folhas formadas apresentavam coloração branca, sem a expansão dos limbos.

Após 60 dias de cultivo in vitro, os menores valores para o comprimento dos brotos, $1,78 \mathrm{~cm}$, foram registrados no meio MS adicionado de ANA. Entretanto, KISS et al. (1995) e PRAXEDES et al. (2001) utilizando o mesmo meio de cultura, para abacaxi comestível, registraram brotos que atingiram, em média $7,74 \mathrm{~cm}$ e $2,44 \mathrm{~cm}$ de comprimento, respectivamente, após apenas, 30 dias de incubação in vitro.

BARBOZA \& CALDAS (2001) relataram que no escuro, os entrenós do talo da plântula do abacaxizeiro comestível se alongaram, separando os nós que, normalmente, em presença de luz, permanecem próximos uns aos outros. GEORGE (1993b) acrescenta que, além da maior separação entre os nós, o estiolamento também pode aumentar, nas gemas, a sensibilidade a auxinas, conseqüentemente, a freqüência com que elas podem ser enraizadas. BARBOZA \& CALDAS (2001) ressaltam que há muito tempo esse comportamento tem sido observado em plantas crescendo no escuro, e que para fins de micropropagação, a separação dos nós facilita o desenvolvimento de gemas axilares e a manipulação de plântulas regeneradas. O mesmo comportamento foi observado para a espécie de abacaxi ornamental estudada. 
Ocorreu alongamento dos entrenós do talo, separando os nós, o que conseqüentemente facilitou o desenvolvimento das gemas axilares e a manipulação das plântulas obtidas.

Para regeneração de plântulas por meio do estiolamento do broto, BARBOZA \& CALDAS (2001) testaram o efeito de número de nós por broto, tendo verificado que em todos os tratamentos houve uma tendência à redução do número de plântulas regeneradas por nó, à medida que o número de nós em cada broto aumentava. Os autores verificaram que nos brotos com 1 a 4 nós, o número de plântulas regeneradas por nó variou de 0,9 a 1,4/explante. Comparando-se esses resultados com os obtidos no presente trabalho, verifica-se a regeneração de 0,60 plântula por nó, após 30 dias de inoculação no meio sem reguladores de crescimento, enquanto os autores obtiveram 0,90 no mesmo meio. No meio contendo BAP a $8,88 \mu \mathrm{M}$, eles obtiveram, em brotos contendo 1 a 4 nós, 1,30 plântula regenerada/nó, enquanto no presente trabalho foi registrada 1,01 plântula.

$\mathrm{O}$ efeito de diferentes concentrações de BAP, na micropropagação de abacaxi comestível (Ananas comosus), tem sido relatado, e de acordo com ALBUQUERQUE et al. (2000), a adição de BAP no meio de cultura foi essencial para a regeneração de plantas a partir da proliferação de gemas axilares dessa espécie. PEREIRA et al. (2001) registraram o maior número de brotos para multiplicação in vitro de abacaxi comestível, variedade Perolera, no meio de cultura contendo $5 \mu \mathrm{M}$ de BAP. Os autores também obtiveram a regeneração de plântulas, a partir de segmento estiolado, em meio de cultura sem a adição de reguladores de crescimento. BARBOZA \& CALDAS (2001), trabalhando com segmentos estiolados para a micropropagação de abacaxi comestível, observaram que o BAP promoveu um maior número de plantas por nó e por segmento nodal, quando comparado com a 6-furfurilaminopurina (CIN), ou em combinação do BAP com ANA.

Entretanto, esses autores constataram que, no tratamento sem reguladores de crescimento, ocorreu menor regeneração de plântulas por nó. Portanto, tais resultados confirmam os obtidos neste trabalho, os menores valores para o número de plântulas regeneradas por nó também foram verificados no meio de cultura sem a adição de reguladores de crescimento. GRATTAPAGLIA\& MACHADO (1998) citam o BAP como sendo uma citocinina adequada para a multiplicação de partes aéreas e para a indução de gemas adventícias. Para o abacaxi ornamental, o aumento da concentração de BAP no meio de cultura, resultou em um acréscimo no número médio de plântulas regeneradas por nó, a partir dos 45 dias de cultivo. Entretanto, para A. comosus, KISS et al. (1995) registraram os maiores valores no meio contendo CIN, em relação ao BAP.

BORGES et al. (2003), trabalhando com a micropropagação de A. lucidus, pelo método tradicional, isto é, a partir de gemas axilares, verificaram que acréscimos de meio líquido, efetuados aos 15 e 30 dias de cultivo, proporcionaram a maior média de número de brotos $(32,6$ brotos/explante) após a realização de três subcultivos sucessivos, com duração de 30 dias cada. BRAGA et al. (2003), estudando a micropropagação in vitro de $A$. comosus var. bracteatus, também pelo método tradicional, obtiveram as maiores taxas $(4,6)$ após 40 dias de inoculação no meio contendo 4,44 $\mu \mathrm{M}$ de BAP. Considerando-se que, 60 dias após a inoculação dos explantes em meio MS sem a adição de reguladores de crescimento, foram obtidos, em média, 9,80 nós por explante, e que estes nós, cultivados em meio MS contendo esta mesma concentração de BAP, após 45 dias regeneraram, em média, 1,13 plântula, podese estimar uma taxa de multiplicação de 11,1 ao final de 105 dias. Entretanto, utilizando-se o meio contendo BAP, a $13,32 \mu \mathrm{M}$, a taxa de multiplicação seria 17,2.

\section{CONCLUSÕES}

1. O método de estiolamento de segmentos nodais e regeneração de plântulas é viável para a multiplicação in vitro do abacaxi ornamental $A$. comosus var. bracteatus; 2. O meio MS, sem a adição de regulador de crescimento, é adequado para indução in vitro de estiolamento de brotos em $A$. comosus var. bracteatus;

3. O estiolamento in vitro de $A$. comosus var. bracteatus pode ser obtido eficazmente sem a adição de AIA, AIB ou ANA; 4. O meio MS, acrescido de 13,32 $\mu \mathrm{M}$ de BAP, é eficiente para regeneração in vitro de plântulas de A. comosus var. bracteatus, a partir de segmentos nodais estiolados no meio MS sem regulador de crescimento.

\section{AGRADECIMENTOS}

Os autores agradecem à Financiadora de Estudos e Projetos (FINEP)/Fundo Nacional de Desenvolvimento Científico e Tecnológico (FNDCT), que, por meio do projeto "Centro Agroflores de Inovação Tecnológica", financiou a pesquisa e ao Conselho Nacional de Desenvolvimento Científico e Tecnológico (CNPq), pela concessão de bolsas.

\section{REFERÊNCIASBIBLIOGRÁFICAS}

ALBUQUERQUE, C.C.; CAMARA, T.R.; MENEZES, M.; WILLADINO, L.; MEUNIER, I.; ULISSES, C. Cultivo in vitro de ápices caulinares de abacaxizeiro para limpeza clonal em relação à fusariose. Scientia Agricola, Piracicaba, v.57, n.2, p.363-366, 2000.

BORGES, N.S.S. Influência da adição de meio de cultura líquido no crescimento e desenvolvimento de gemas de abacaxi ornamental (Ananas lucidus Miller). Fortaleza: Universidade Federal do Ceará, 2000, 44p. Monografia (Graduação em Agronomia)

BORGES, N.S.S.; CORREIA, D.; ROSSERRI, A.G. Influência do meio bifásico na multiplicação de gemas e no alongamento de brotos in vitro de Ananas lucidus Miller. Revista Brasileira de Horticultura Ornamental, Campinas, v.9, n.1, p.37-44, 2003.

BARBOZA, S.B.S.C.; CALDAS, L.S. Estiolamento e regeneração na multiplicação in vitro de abacaxizeiro híbrido PE x SC-52. Pesquisa Agropecuária Brasileira, Brasília, v.36, n.3, p.417-423, 2001

BRAGA, E. P.; MORAIS, J. P. S.; CARVALHO, A. C. P. P.; SANTOS, M. R. A. Avaliação dos efeitos do número de 
explantes, do meio de cultura e do fotoperíodo na multiplicação in vitro de abacaxi ornamental (Ananas bracteatus). In: CONGRESSO BRASILEIRO DE FLORICULTURA E PLANTASORNAMENTAIS, 14,CONGRESSOBRASILEIRO DECULTURADETECIDOS DEPLANTAS, 1, Lavras, 2003. Anais... Lavras, UFLA, 2003.p.312.

CABRAL., J. R. S.; MATOS, A. P.; SOUTO, G. F. Reação de germoplasma de abacaxi à inoculação com Fusarium moniliforme var. Subglutinans. Pesquisa Agropecuária Brasileira, Brasília, v.20, n.7, p.787-791, 1985.

CALDAS, L.S.; HARIDASAN, P.; FERREIRA, M.E. Meios nutritivos. In: TORRES, A.C.; CALDAS, L.S. (ed.). Técnicas e aplicações da cultura de tecidos de plantas. Brasília:ABCTP/EMBRAPA-CNPH, 1990. p.37-70.

CORREIA, D; OLIVEIRA, P.M.A.; RIBEIRO, K.A.; SILVEIRA, M.R.S. Avaliação da multiplicação in vitro do abacaxi ornamental (Ananas lucidus Miller). Fortaleza: Embrapa Agroindústria Tropical, 1999a. 2p. (Pesquisa em Andamento, 56)

CORREIA, D; OLIVEIRA, P.M.A.; RIBEIRO, K.A.; ROSSETTI,A.G.; SILVEIRA, M.R.S. Influência dos meios de cultura sólido e líquido no alongamento de brotos in vitro de abacaxi ornamental (Ananas lucidus Miller). Fortaleza: Embrapa Agroindústria Tropical, 1999b. 3p. (Pesquisa em Andamento, 57).

GEORGE, E.F. Factors affecting growth and morphogenesis. In: Plant propagation by tissue culture. 2. ed., Edington: Exegetics, 1993a.p.183-230
GEORGE, E.F. Rooting and establishment. In: Plant propagation by tissue culture.

2. ed., Edingtion: Exegetics, 1993b. p.670-732.

GRATTAPAGLIA, D.; MACHADO, M.A Micropropagação. In: TORRES, A.C.; CALDAS, L.S.; BUSO, J.A. (ed.). Cultura de tecidos e transformação genética de plantas. Brasília: Embrapa-SPI:Embrapa-CNPH, 1998. v.1,p.183-260.

KISS, E.; KISS, J.; GYULAI, G.; HESZKY, L.E. A novel method for rapid micropropagation of pineapple. HortScience, Alexandria, v.30, n.1., p.127-129, 1995.

MOREIRA, M.A.; ANJOS SOBRINHO, A. dos; SILVA, A. B. da; PASQUAL, M. Indução ao estiolamento in vitro de abacaxi cv. Primavera. In: CONGRESSO BRASILEIRO DE FISIOLOGIA VEGETAL, 6., Belém, 1997. Resumos...Belém, Sociedade Brasileira de Fisiologia Vegetal, 1997. p.380.

MURASHIGE, T.; SKOOG, F. A revised medium for rapid growth and bioassays with tobacco tissue cultures. Physiologia Plantarum, Copenhagen, v.15, p.473-497, 1962.

PEREIRA, F.D.; BRAGA, M.F; AS, M.E.L.; ALCINO, O.A.G.; COLENGHI, I.C. Influence of BAP and NAA on multiplication of pineapple cv. Perolera, from in vitro etiolated shoots. Bioscience Journal, Uberlândia, v.17, n.2,p.49-60, 2001.

PRAXEDES, S.C.; SILVAJR.,A.F.; FIGUEIREDO, M. de L.; CÂMARA, F.A.A.; OLIVEIRA, O.F. de. Estiolamento in vitro do abacaxizeiro Pérola em Presença de ANA e AIA. Caatinga, Mossoró, v.14, n.1/2, p. 13-15, 2001. 